\title{
Discrepancy Between the Demand and Supply of Intensive Care Unit Beds in South Korea from 2011 to 2019: A Cross-Sectional Analysis
}

\section{Noo Ree Cho}

Gachon University Gil Medical Center

Wol Seon Jung

Gachon University Gil Medical Center

\section{Hee Yeon Park}

Gachon University Gil Medical Center

Jin Mo Kang

Gachon University Gil Medical Center

Dai Sik Ko ( $\nabla$ daisik.ko@gilhospital.com )

Gachon University Gil Medical Center https://orcid.org/0000-0002-8858-4025

\section{Sang Tae Choi}

Gachon University Gil Medical Center

\section{Research}

Keywords: bed supply, cross-sectional studies, Health Insurance Review \& Assessment Service, intensive care unit, occupancy, population, Republic of Korea, supply

Posted Date: June 28th, 2021

DOI: https://doi.org/10.21203/rs.3.rs-614531/v1

License: (c) (i) This work is licensed under a Creative Commons Attribution 4.0 International License. Read Full License 


\section{Abstract}

Background: Intensive care unit (ICU) bed availability is key to critical patient care. Considering the rapidly aging population in South Korea, it is important to establish whether the current ICU bed availability meets its demand.

Methods: We evaluated the 9-year trend in ICU bed rates and bed-days in South Korea between 2011 and 2019 in a population-based cross-sectional analysis, using data from the Korean Health Insurance Review \& Assessment Service and Statistics database. We described changes in ICU bed rates in adult ( $\geq 20$ years) and older adult ( $\geq 65$ years) populations. ICU bed-days were categorized similarly and were used to predict future ICU bed demands.

Results: The ICU bed rate was higher in 2011 than 2019 (23.3 and 20.2 per 100,000 adults; 161.2 and 107.5 per 100,000 older adults, respectively). Conversely, the number of ICU bed-days was lower in 2011 than 2019 (100.5 and 137.8 per 1,000 adults; 59.0 and 86.1 per 1,000 older adults, respectively). In 2019, the regional differences in the ICU bed rate and ICU bed-days nearly doubled and tripled, respectively. The occupancy rate of ICU beds in South Korea is expected to rise to $97.7 \%$ in 2030 .

Conclusions: Our study revealed a significant discrepancy between the demand and supply of ICU beds in South Korea, necessitating significant action.

\section{Background}

Access to critical care is a crucial element of contemporary healthcare systems [1]. The demand for critical care capacity is increasing worldwide due to the significant aging of populations, with the accompanying increase in associated comorbidities, the development of life-sustaining treatment modalities, and the changes in perception regarding the role of intensive care units (ICUs) [2, 3]. In many countries, the median age of the entire population admitted to the ICU is currently 65 years or older [4]. Recent studies have revealed that the increase in ICU admission is attributable to older patients (older than 80 years) $[5,6]$. As these patients account for a significant proportion of hospitalizations, as well as for ICU treatment days, this increase may profoundly affect the utilization of ICU resources $[6,7]$

The growing demand for ICU resources can only be met by increasing the total capacity of ICUs [8, 9]. ICU bed shortage is associated with a greater risk in early readmission and higher refusal rates of patients $[10,11]$. As aging populations are expected to demand critical care services consistently and increasingly [12], an accurate prediction of future demand levels is necessary to avoid insufficient supply. In Australia, Corke et al. [13] predicted that the expected that the proportion of patients aged over 80 years admitted to ICUs would increase to $26.3 \%$ by 2030 .

South Korea is one of the world's fastest-aging countries [14]. Park et al. [15] investigated the ICU admission rate, total cost, and utilization of management procedures, such as mechanical ventilation, renal replacement therapy, and extracorporeal membrane oxygenation in South Korea, and showed that these variables increased from 2009 to 2014. However, there have been no reports regarding the relationship between the increase in the number of the ICU beds and the increase in the utilization of ICU facilities. Therefore, in this study, we investigated the trends in ICU bed supply and ICU bed-days from 2011 to 2019 in the adult population as follows: (1) classification of the population into adults and older adults, (2) evaluating changes in the number of ICU beds and duration of ICU stay (ICU bed-days) each year, (3) evaluating geographical differences in the number of ICU beds and ICU bed-days, and (4) prediction of future ICU demands.

\section{Methods}




\section{Data source}

We performed a cross-sectional study of the ICU bed supply and ICU bed-days from 2011 to 2019 in South Korea. We obtained data on ICU admission from the Health Insurance Review and Assessment Service (HIRA) database, a database that encompasses South Korea's entire population, including the number of admissions, age of patients, and duration of ICU stay (bed-days). Population data, counts of hospitals, hospital beds, and ICU beds were obtained from Statistics Korea. Since the records did not contain any identifying information, this study was exempted from ethical review by the Gachon University Gil Medical Centre's ethics review board.

\section{Definitions and variables}

We defined hospitals as hospitals with ICUs. Clinics were excluded and hospital beds were defined as licensed hospital beds. ICU beds included an aggregation of all ICU beds, excluding neonatal ICU beds (Fig. 1). In South Korea, paediatric ICUs are extremely limited and most paediatric patients who need intensive care are admitted to general ICUs.

Occupancy rates were defined as the number of ICU bed-days divided by the number of available ICU bed-days. The number of available bed-days was calculated as the total number of beds multiplied by 365 days, assuming that every bed was available for daily use [16].

The changes in ICU beds were described at the national level and in a 16-administrative-district level with two population groups: adults (aged $\geq 20$ years) and older adults (aged $\geq 65$ years). South Korea comprises 17 administrative districts; however, due to the relocation of central administrative agencies in 2012, the Sejong-si region did not contain an ICU hospital and its data was merged with that of the adjacent administrative district, Chungcheongnam-do. Annual ICU bed rates were calculated as population-based rates by weighting raw values to national and administrative district populations for each year in the study. Annual changes in counts of ICU bed-days in national and administrative districts are described for both adults and older adults. Since the number of admissions does not represent the utilization of ICU resources, we evaluated occupied ICU bed-days.

\section{Statistical analysis}

Data were analyzed using R (version 3.6.0, Vienna, Austria). We examined temporal trends in ICU bed number growth at the national and regional levels. At the national level, we summarized the annual number of hospitals, hospital beds, ICU beds, adult and older adult population sizes, ICU beds per adult population, ICU beds per older adult population, ICU bed-days for the whole population, ICU bed-days per adult population, ICU bed-days per older adult population, and occupancy rates. At the regional level, we calculated the number of ICU beds, ICU beds per adult population, ICU beds per older adult population, ICU bed-days per adult population, and ICU bed-days per older adult population.

We reported the temporal trends in the national and administrative district averages for each variable using Joinpoint regression analysis (version 4.8.0.1; National Cancer Institute; https://surveillance.cancer.gov/joinpoint/) [17]. Trends spanning from 2011 to 2019 were computed as the mean annual percentage change. Shorter time segment trends were computed as the annual percentage change. This annual percentage change and mean annual percentage change for each variable were expressed as the percentage change with a 95\% confidence interval (CI). All hypothesis testing was two-tailed, with a statistical significance set at $P<0.05$.

At the administrative district level, the geographic inequality in ICU beds and ICU bed-days was quantified by comparing the 10th and 90th percentiles for each variable among all administrative districts [18]. The difference between these two percentiles was used to indicate the degree of absolute geographic inequality, representing the absolute magnitude of the gap between high- and low-prescribing administrative districts for each variable. The ratio 
between the 90 th and 10 th percentiles was used to assess the relative degree of geographic inequality between administrative districts for each variable.

We projected ICU bed-days in 2020, 2030, and 2040 based on the national and regional ICU bed-days between 2011 and 2019, using a time-series statistical procedure, the Autoregressive Integrated Moving Average (ARIMA) model [19]. The $95 \% \mathrm{Cl}$ of all population parameters was also derived. We used the R package 'forecast' for this analysis.

\section{Results}

\section{National temporal trends}

Temporal trends in ICU bed number growth and ICU bed-days are shown in Table 1. From 2011 to 2019, there was an increase in the number of hospitals in South Korea (from 1,694 to 1,845; 8.9\% growth) and a decrease in the total number of hospital beds (from 328,647 to 315,$524 ; 4.0 \%$ ). Moreover, there was a decrease in the total number of ICU beds (from 9,188 to 8,$626 ; 6.1 \%$ ). In 2011, the adult population in South Korea was $39,377,310$, resulting in an overall rate of 23.3 ICU beds per 100,000 persons. By 2019, the adult population had increased to $42,723,937$, which resulted in an overall rate of 20.2 ICU beds per 100,000 adults. The older adult population was 5,700,972 in 2011, resulting in an overall rate of 161.2 ICU beds per 100,000 older adults. In 2019, the older adult population increased to 8,026,915, resulting in a substantial decrease to 53.7 per 100,000 population. In 2011 , the ICU bed-days for the adult population were $1,588,606$, which increased to $2,181,958$ in 2019 . The ICU bed-days for the older adult population were 967,086 in

2011 , which increased to $1,431,344$ in 2019 . There was an increase in occupancy rate by $45.2 \%$, from $49.3 \%$ in 2011 to $71.6 \%$ in 2019. 
Table 1

Hospitals, hospital beds, intensive care unit beds, population, and occupancy rate between 2011 and 2019

\begin{tabular}{|c|c|c|c|c|c|c|c|c|c|}
\hline & 2011 & 2012 & 2013 & 2014 & 2015 & 2016 & 2017 & 2018 & 2019 \\
\hline Hospitals & 1,694 & 1,743 & 1,775 & 1,804 & 1,833 & 1,855 & 1,810 & 1,818 & 1,845 \\
\hline $\begin{array}{l}\text { Hospital } \\
\text { beds }\end{array}$ & 328,647 & 333,584 & 334,215 & 338,862 & 338,349 & 340,491 & 319,581 & 317,406 & 315,524 \\
\hline ICU beds & 9,188 & 8,905 & 8,861 & 8,511 & 8,086 & 8,308 & 8,318 & 8,417 & 8,626 \\
\hline $\begin{array}{l}\text { ICU bed } \\
\text { proportion }\end{array}$ & 0.028 & 0.027 & 0.027 & 0.025 & 0.024 & 0.024 & 0.026 & 0.027 & 0.027 \\
\hline $\begin{array}{l}\text { Population } \\
\gtrless 20 \text { years } \\
(100 K)\end{array}$ & 393.8 & 398.3 & 402.9 & 407.5 & 412.1 & 416.5 & 420.4 & 423.9 & 427.2 \\
\hline $\begin{array}{l}\text { Population } \\
\geq 65 \text { years } \\
(100 K)\end{array}$ & 57.0 & 59.8 & 62.5 & 65.2 & 67.8 & 70.0 & 73.6 & 76.5 & 80.3 \\
\hline \multicolumn{10}{|l|}{$\begin{array}{l}\text { Hospital } \\
\text { beds per } \\
100 \mathrm{~K}\end{array}$} \\
\hline $\begin{array}{l}\text { Population } \\
\geq 20 \text { years }\end{array}$ & 834.6 & 837.5 & 829.6 & 831.6 & 821.0 & 817.5 & 760.2 & 748.7 & 738.5 \\
\hline $\begin{array}{l}\text { Population } \\
\geq 65 \text { years }\end{array}$ & $5,764.8$ & $5,578.3$ & $5,346.6$ & $5,196.8$ & $4,994.0$ & $4,867.2$ & $4,344.4$ & $4,148.9$ & $3,930.8$ \\
\hline \multicolumn{10}{|l|}{$\begin{array}{l}\text { ICU beds } \\
\text { per 100K }\end{array}$} \\
\hline $\begin{array}{l}\text { Population } \\
\geq 20 \text { years }\end{array}$ & 23.3 & 22.4 & 22.0 & 20.9 & 19.6 & 19.9 & 19.8 & 19.9 & 20.2 \\
\hline $\begin{array}{l}\text { Population } \\
\geq 65 \text { years }\end{array}$ & 161.2 & 148.9 & 141.8 & 130.5 & 119.3 & 118.8 & 113.1 & 110.0 & 107.5 \\
\hline $\begin{array}{l}\text { ICU bed } \\
\text { days (K) }\end{array}$ & $1,655.0$ & $1,725.4$ & $1,765.8$ & $1,831.3$ & 1,973.0 & $2,088.2$ & $2,156.3$ & $2,241.7$ & $2,252.9$ \\
\hline $\begin{array}{l}\text { Population } \\
\geq 20 \text { years } \\
(\mathrm{K})\end{array}$ & 1,588.6 & $1,660.1$ & 1,699.2 & $1,764.0$ & $1,903.4$ & $2,016.9$ & $2,086.6$ & $2,173.9$ & $2,182.0$ \\
\hline $\begin{array}{l}\text { Population } \\
\geq 65 \text { years } \\
(\mathrm{K})\end{array}$ & 967.1 & $1,034.4$ & $1,062.3$ & $1,106.2$ & $1,207.0$ & $1,285.2$ & $1,352.3$ & $1,427.4$ & $1,431.3$ \\
\hline $\begin{array}{l}\text { Occupancy } \\
\text { rate (\%) }\end{array}$ & 49.3 & 53.1 & 54.6 & 59.0 & 66.8 & 68.9 & 71.0 & 73.0 & 71.6 \\
\hline
\end{tabular}

\section{Regional differences in ICU bed-numbers}

Over 9 years, the ICU bed rate per 100,000 adult population decreased by a mean and standard deviation (SD) of 13.5\% (12.1\%) among administrative districts, while absolute geographic inequality decreased from 15.3 in 2011 to 13.2 in 2019, respectively. However, relative geographic inequality was not different (1.9) (Table 2). Regarding the 16 
administrative districts, Joinpoint analysis indicated that the ICU bed rate per 100,000 adult population increased in only one administrative district (Incheon) (6.2\%), while the rate decreases in another eight administrative districts (50.0\%). No significant difference was observed in seven administrative districts (43.8\%). The most significant decrease in the annual average percentage change in the ICU bed rate per 100,000 adult population was 5.3\%, in Gyeongsangnam-do ( $95 \% \mathrm{Cl},-5.5$ to -0.8 ) (Fig. 2A and Supplementary e-Table 1). Furthermore, the highest ICU bed rates per 100,000 adult population were found in Gangwon-do (34.7 and 30.4 in 2011 and 2019, respectively). The lowest ICU bed rates per 100,000 adult population were found in Ulsan, which were 17.5 and 17.1 in 2011 and 2019 , respectively (Fig. 2A and Supplementary e-Table 1). 
Table 2

Trends in intensive care unit beds and bed-days for administrative districts in South Korea, 2011-2019a

\begin{tabular}{|c|c|c|c|c|c|c|c|c|}
\hline \multirow[b]{2}{*}{$\begin{array}{l}\text { Characteristics by } \\
\text { Year }\end{array}$} & \multirow[b]{2}{*}{$\begin{array}{l}\text { Mean } \\
(S D) \\
{[\text { Median] }}\end{array}$} & \multicolumn{2}{|c|}{ Percentile } & \multicolumn{2}{|c|}{$\begin{array}{l}\text { Geographical } \\
\text { Inequality }\end{array}$} & \multicolumn{3}{|c|}{$\begin{array}{l}\text { Administrative Districts with } \\
\text { Statistically Significant Change }\end{array}$} \\
\hline & & 10th & 90th & Absolute $^{c}$ & Relative $^{\mathrm{d}}$ & Decrease $^{e}$ & Steady ${ }^{f}$ & Increase \\
\hline \multicolumn{9}{|l|}{$\begin{array}{l}\text { ICU bed rate per } \\
100 \mathrm{~K} \text { of population } \\
\geq 20 \text { years }\end{array}$} \\
\hline 2011 & $\begin{array}{l}24.8(5.7) \\
{[24.8]}\end{array}$ & 17.6 & 32.9 & 15.3 & 1.9 & & & \\
\hline 2019 & $\begin{array}{l}21.3(5.0) \\
{[21.1]}\end{array}$ & 15.0 & 28.2 & 13.2 & 1.9 & & & \\
\hline \multirow[t]{2}{*}{$\begin{array}{l}\text { Change (2011- } \\
\text { 2019),\% }\end{array}$} & $\begin{array}{l}-13.5 \\
(12.1)\end{array}$ & -24.8 & -7.1 & & & & & \\
\hline & {$[-13.6]$} & & & & & & & \\
\hline $\begin{array}{l}\text { Trend (2011-2019), } \\
\text { No. (\%) }\end{array}$ & & & & & & $8(50.0)$ & $\begin{array}{l}7 \\
(43.8)\end{array}$ & $1(6.2)$ \\
\hline \multicolumn{9}{|l|}{$\begin{array}{l}\text { ICU bed rate per } \\
100 \mathrm{~K} \text { of population } \\
\geq 65 \text { years }\end{array}$} \\
\hline 2011 & $\begin{array}{l}166.7 \\
(44.5) \\
{[163.6]}\end{array}$ & 122.0 & 220.3 & 98.4 & 1.8 & & & \\
\hline 2019 & $\begin{array}{l}110.2 \\
(28.7) \\
{[101.9]}\end{array}$ & 81.3 & 140.8 & 59.5 & 1.7 & & & \\
\hline \multirow{2}{*}{$\begin{array}{l}\text { Change (2011- } \\
\text { 2019), \% }\end{array}$} & $-33.0(9.6)$ & -45.5 & -22.7 & & & & & \\
\hline & {$[-32.9]$} & & & & & & & \\
\hline $\begin{array}{l}\text { Trend (2011- } \\
\text { 2019), No. (\%) }\end{array}$ & & & & & & $14(87.5)$ & $\begin{array}{l}2 \\
(12.5)\end{array}$ & $0(0)$ \\
\hline \multicolumn{9}{|l|}{$\begin{array}{l}\text { ICU bed days of } \\
\text { population } \geq 20 \\
\text { years }(K)\end{array}$} \\
\hline 2011 & $\begin{array}{l}100.5 \\
(111.1) \\
{[61.3]}\end{array}$ & 34.5 & 111.8 & 77.3 & 3.2 & & & \\
\hline 2019 & $\begin{array}{l}137.8 \\
(133.1) \\
{[98.6]}\end{array}$ & 50.1 & 150.6 & 100.6 & 3.0 & & & \\
\hline \multirow[t]{2}{*}{$\begin{array}{l}\text { Change (2011- } \\
\text { 2019), \% }\end{array}$} & $\begin{array}{l}47.7 \\
(38.9)\end{array}$ & 11.8 & 89.2 & & & & & \\
\hline & [31.5] & & & & & & & \\
\hline
\end{tabular}




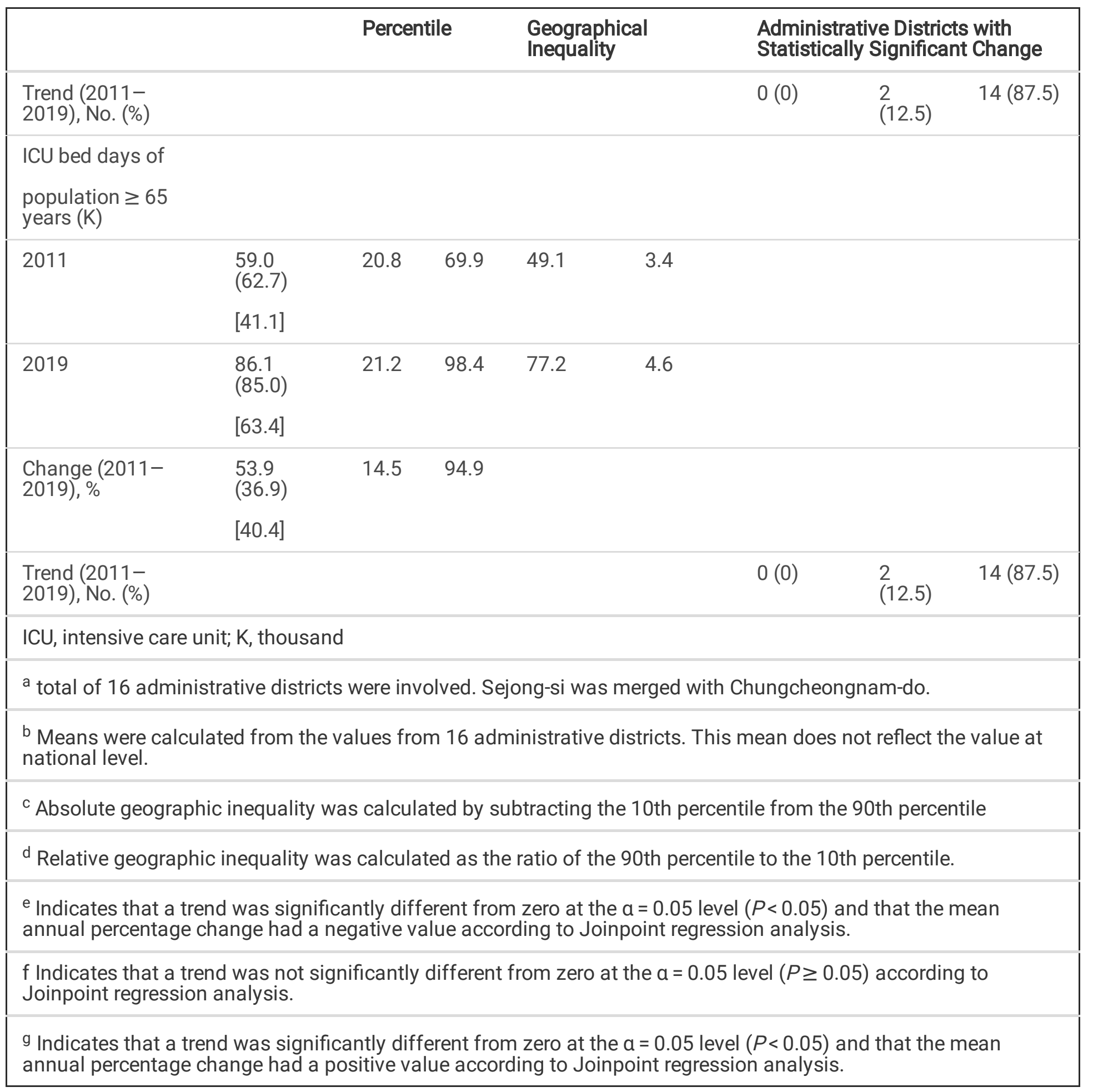

There was a decrease in the ICU bed rates per 100,000 older adults by a mean (SD) of 33.0\% (9.6\%) among administrative districts. The absolute geographic inequality decreased from 98.4 to 59.5 from 2011 to 2019 , and the relative geographic inequality decreased from 1.8 to 1.7 (Table 2). Joinpoint analysis indicated that the ICU bed rate per 100,000 older adults decreased in 14 administrative districts (87.5\%). The most significant decrease in the annual average percentage change in ICU bed rate per 100,000 adult population was observed in Gyeongsangnam-do: 8.1\% $(95 \% \mathrm{Cl},-9.2$ to -6.9$)$ (Supplementary e-Table 2). The highest ICU bed rates per 100,000 older adult population were found in Gwangju; they were 263.2 and 178.0 in 2011 and 2019, respectively. The lowest ICU bed rates per 100,000 people in the older adult population were found in Chungcheongnam-do; they were 91.1 and 70.9 in 2011 and 2019, respectively (Fig. 2B and Supplementary e-Table 2). 


\section{Regional differences in ICU bed-days}

The number of ICU bed-days in the adult population increased by a mean (SD) of $47.7 \%$ (38.9\%) among administrative districts, while absolute geographic inequality increased from 77.3 in 2011 to 100.6 in 2019. However, the relative geographic inequality decreased from 3.2 to 3.0 (Table 2). Joinpoint analysis indicated that the number of ICU beddays in the adult population increased in 14 administrative districts (87.5\%) and no significant difference was seen in two administrative districts (12.5\%). The most significant increase in the annual average percentage change in ICU bed-days in the adult population was $13.0 \%$ in Gwangju (95\% Cl, 7.9 to 18.3) (Supplementary e-Table 3). The highest number of ICU bed-days in the adult population was observed in Seoul; they were 425,600 and 510,100 in 2011 and 2019 , respectively. On the other hand, the lowest number of ICU bed-days in the adult population was 33,000 in Ulsan in 2011 and 34,500 in Jeju-do in 2019 (Fig. 2C and Supplementary e-Table 3).

The number of ICU bed-days in the older adult population increased by a mean (SD) of $53.9 \%$ (36.9\%) among administrative districts from 2011 to 2019 . The absolute geographic inequality increased from 49.1 in 2011 to 77.2 in 2019 , while the relative geographic inequality increased from 3.4 to 4.6 during this period (Table 2). Joinpoint analysis indicated that the number of ICU bed-days in the older adult population increased in 14 administrative districts (87.5\%) while no significant difference was observed in two administrative districts (12.5\%). The most significant increase in the annual average percentage change in the number of ICU bed-days in the older adult population was observed in Gwangju, which was $12.8 \%$ (95\% Cl, 8.2 to 17.5) (Supplementary Table 4). The largest numbers of ICU bed-days in the older adult population were 231,400 and 315,700 in 2011 and 2019, respectively; both these numbers were observed in Seoul. The smallest numbers of ICU bed-days in the older adult population were 2,800 and 5,400 in 2011 and 2019 , respectively, both in Chungcheongnam-do (Fig. 2D and Supplementary e-Table 4).

\section{South Korea's future ICU demands}

We analyzed and predicted the number of ICU bed-days in 2020, 2030, and 2040 based on the number of ICU bed-days from 2011 to 2019 using the ARIMA model. At a national level, the predicted number of ICU bed-days of the population aged under 45 years was stable over the prediction period. However, the number of ICU bed-days of the population aged 45 years and older was predicted to increase. Specifically, the population aged $\geq 80$ years was expected to account for the largest share of ICU bed-days in 2030 (Fig. 3A). Summing the total number of ICU bed-days for each age group provided the total number of expected ICU bed-days (Fig. 3B). In 2030, the number of ICU bed-days was expected to increase (by 36.5\%) to 3,075,100 days from 2,252,900 days in 2019 (Supplementary e-Table 5). Assuming no change in the number of ICU beds in 2030 , the occupancy rate was calculated as $97.7 \%$. A higher occupancy rate, particularly occupancy over $80 \%$, has been reported to show a direct relationship with ICU and hospital mortality and ICU readmission within 7 days of discharge [20]. Therefore, we calculated the predicted ICU beds in 2030 assuming an occupancy rate of $80 \%$, which was $10,531.1$, representing a $22.1 \%$ increase from 2019 . At the regional level, there were eight administrative districts (50\%) with a prediction of occupancy rate over $80 \%$ in 2030 (Supplementary e-Table 5). The administrative districts with expected occupancy rates over 100\% in 2030 included Daegu (116.1\%), Chungcheongnam-do (142.6\%), and Gyeongsangnam-do (105.3\%).

\section{Discussion}

This study demonstrated the changes in the number of ICU beds and ICU bed-days at a national and at administrative district level over a period of 9 years. The number of ICU beds available serve as a cornerstone for providing life-saving support for critically ill patients [21]. Based on this concept, we investigated whether there was a discrepancy between the demand for critical care and ICU bed supply. We showed that the number of hospitals and hospital beds increased nationally. However, the number of ICU beds, the ICU bed rate per adult population, and the ICU bed rate per older adult 
population decreased nationally over the 9-year period of investigation. The number of ICU bed-days in the adult and older adult population increased during the same period. A significant discrepancy was found between the supply and demand of ICU beds in South Korea.

In the US, the number of acute care hospitals decreased, while the number of ICU beds substantially increased from 2000 to 2009 (15.1\%) [22]. The ICU bed rate for individuals aged $\geq 20$ years remained constant, while that for individuals aged $\geq 65$ years decreased by $2.0 \%$ over this period in the US. In South Korea, the number of ICU beds, ICU bed rate per adult population, and ICU bed rate per older adult population decreased from 2011 to 2019 , by $6.1 \%$, $13.3 \%$, and $33.3 \%$, respectively. The reason for this decline is the decrease in the number of ICU beds. However, the aging of the population seems to be another major factor. The population of South Korea is aging rapidly, and the population aged 65 years or older is expected to comprise $20 \%$ of the total population in 2025 [23]. In the US, the increase in the percentage of older adult patients affected the utilization of ICU resources, including ICU beds and specialists [7, 9]. In the Netherlands, the percentage of hospital admissions of older adults rose between 2005 and 2014; however, the percentage of ICU admissions and ICU bed-days remained stable. In our study, the older adult population size and their number of ICU bed-days increased by 40.9\% and 48.0\%, respectively, from 2011 to 2019.

Our data also revealed regional disparities in the number of ICU beds and ICU bed-days among the adult and older adult populations. The 90th percentile values of the ICU bed rate per adult population and per older adult population were almost twice the value of the 10th percentile in 2019. Regarding the number of ICU bed-days in the adult population, the regional difference was 3.0 times the difference of the 10th percentile in 2019 . Notably, disparities in the number of ICU bed-days for the older adult population between administrative districts widened in 2019 (4.6 times of the 90th percentile to the 10th percentile) compared to 2011 (3.4 times of the 90th percentile to the 10th percentile). We expressed the intensity of ICU bed rates and ICU bed-days visually using a map of South Korea (Fig. 2) and observe that areas with high-intensity ICU bed rates were not the same as those with high-intensity ICU bed-days. In 2019, the sum of the number of ICU bed-days of two regions, Seoul and Gyeonggi-do, constituted $42.7 \%$ of the total number of ICU bed-days of the adult population (Supplementary e-Table 3) and $40.9 \%$ of the total number of ICU bed-days of the older adult population (Supplementary e-Table 4). As the ICU beds of Seoul and Gyeonggi-do constitute $41.7 \%$ of the total number of ICU beds in South Korea, these regional disparities may reflect the centralization of the healthcare system.

We projected future ICU demands using the ARIMA model, based on the number of ICU bed-days in the 9-year period recorded in the HIRA database. This model has been adopted in previous studies to forecast bed-days by analyzing the retrospective Medicare Health Maintenance Organization data [24] and the Australian and New Zealand Intensive Care Society Core Database [13], which are structurally similar to the HIRA database. We predicted that ICU bed demands will outpace ICU bed supply in 2030, not only in Seoul and Gyeonggi-do, where healthcare resources are concentrated, but also in Daegu, Chungcheongnam-do, and Gyeongsangnam-do. Among them, Chungcheongnam-do (70.9) and Gyeongsangnam-do (78.6) have the lowest ICU bed rates per older adult population (Supplementary e-Table 5). Without proper critical healthcare policies, these regions may experience problems in terms of ICU bed availability.

Studies of ICU bed availability have been conducted extensively, revealing considerable variability worldwide $[9,25]$ even within individual countries $[22,26]$. In Europe, there were 11.5 critical care beds per 100,000 population, with significant differences between countries (Germany: 29.2 and Portugal: 4.2) [25]. In Asia, there were 3.6 critical care beds per 100,000 population, with marked differences according to the World Bank income classification, i.e., a median of 2.3 and 12.3 critical care beds per 100,000 low- and high-income populations, respectively [27]. Among the highincome countries, in 2017, South Korea was ranked third lowest, after Japan (7.3) in terms of the number of ICU beds 
per population. Ohbe et al. [28] reported that the 4-year mean ICU bed occupancy rate did not change from 2015 to 2018 in Japan. In contrast, our results revealed that occupancy rate increased annually in South Korea.

The proportion of the older adult population is fast approaching $20 \%$ of the population of South Korea. However, the proportion of the population aged 65 years and older in Japan was already $23.1 \%$ in $2010 .{ }^{29}$ There were attempts to reform the national healthcare system in order to accommodate the needs of the country's increasing aging population $[30,31]$. South Korea's national health insurance, which covers its whole population, has been utilizing fee-for-service payment with a contract-based healthcare reimbursement system [32]. The reimbursement rate is generally low, particularly the cost for ICU resources, and hospital administrators are reluctant to invest in ICU resources, including beds [33]. Our study revealed that occupancy rate may become ca. 100\% in 2030 if there is no increase in the number of ICU beds.

This study had several limitations. Occupancy rates were calculated by dividing the number of ICU bed-days by the number of bed-days available. The term "bed-days available" indicates "potential" bed-days and is not derived from individual-level data. Additionally, day-based occupancy calculations can cause a misinterpretation of the hospital's capacity [34]. Additionally, our prediction of future ICU demands was based on a study over a relatively short period.

\section{Conclusions}

Our study may inform government organizations about the necessity of planning and preparing for future ICU demands and their short supply. Without implementation of proper healthcare policies in the near future, the healthcare system in South Korea may collapse due to the ICU bed shortage. This may be worse in some administrative districts than in others. This will be inevitable if another pandemic situation, similar to COVID-19, occurs. Therefore, reports at the individual-level from individual hospitals and from each administrative district should be published to help government organizations reform healthcare policies in South Korea.

\section{Abbreviations}

ARIMA

Autoregressive Integrated Moving Average

HIRA

Health Insurance Review and Assessment Service

ICU

intensive care unit

SD

standard deviation

\section{Declarations}

Ethics approval and consent to participate: Since the records did not contain any identifying information, this study was exempted from ethical review by the Gachon University Gil Medical Centre's ethics review board.

Consent for publication: Not applicable

Availability of data and materials: The data that support the findings of this study are available from the corresponding author upon reasonable request.

Page $11 / 16$ 
Competing interests: The authors declare that there are no conflicts of interest.

Funding: This research was supported by grants from the Basic Science Research Program (NRF-2020R1A2C1102433) through the National Research Foundation of Korea Grant funded by the Korean government, Young Medical Scientist Research Grant through the Daewoong Foundation (DY20111P) and the Korea Medical Institute.

Authors' contributions: DSK and STC contributed substantially to the study concept and design. WSJ and HPY acquired data and aided in interpreting the results. DSK and NRC made an analysis of data and drafting the manuscript. JMK and STC revised it critically for important intellectual content.

Acknowledgements: Not applicable

Authors' information:

\section{References}

1. Rhodes A, Chiche JD, Moreno R. Improving the quality of training programs in intensive care: a view from the ESICM. Intensive Care Med. 2011;37:377-9.

2. Adhikari NK, Fowler RA, Bhagwanjee S, Rubenfeld GD. Critical care and the global burden of critical illness in adults. Lancet. 2010;376:1339-134.

3. Piers RD, Azoulay E, Ricou B, Dekeyser Ganz F, Decruyenaere J, Max A, et al. Perceptions of appropriateness of care among European and Israeli intensive care unit nurses and physicians. JAMA. 2011;306:2694-703.

4. Flaatten H, De Lange DW, Artigas A, Bin D, Moreno R, Christensen S, et al. The status of intensive care medicine research and a future agenda for very old patients in the ICU. Intensive Care Med. 2017;43:1319-28.

5. Haas LE, Karakus A, Holman R, Cihangir S, Reidinga AC, de Keizer NF. Trends in hospital and intensive care admissions in the Netherlands attributable to the very older adult in an ageing population. Crit Care. 2015;19:353.

6. Ihra GC, Lehberger J, Hochrieser H, Bauer P, Schmutz R, Metnitz B, et al. Development of demographics and outcome of very old critically ill patients admitted to intensive care units. Intensive Care Med. 2012;38:620-6.

7. Angus DC, Barnato AE, Linde-Zwirble WT, Weissfeld LA, Watson RS, Rickert T, Rubenfeld GD, et al. Use of intensive care at the end of life in the United States: an epidemiologic study. Crit Care Med. 2004;32:638-64.

8. Wunsc H, Angus DC, Harrison DA, Linde-Zwirble WT, Rowan KM. Comparison of medical admissions to intensive care units in the United States and United Kingdom. Am J Respir Crit Care Med. 2011;183:1666-73.

9. Angus DC, Kelley MA, Schmitz RJ, White A, Popovich J Jr, Committee on Manpower for Pulmonary and Critical Care Societies (COMPACCS). Caring for the critically ill patient. Current and projected workforce requirements for care of the critically ill and patients with pulmonary disease: can we meet the requirements of an aging population? JAMA. 2000;284:2762-277.

10. Chrusch CA, Olafson KP, McMillan PM, Roberts DE, Gray PR. High occupancy increases the risk of early death or readmission after transfer from intensive care. Crit Care Med. 2009;37:2753-8.

11. Reignier J, Dumont R, Katsahian S, Martin-Lefevre L, Renard B, Fiancette M, et al. Patient-related factors and circumstances surrounding decisions to forego life-sustaining treatment, including intensive care unit admission refusal. Crit Care Med. 2008;36:2076-83.

12. Needham DM, Bronskill SE, Calinawan JR, Sibbald WJ, Pronovost PJ, Laupacis A. Projected incidence of mechanical ventilation in Ontario to 2026: Preparing for the aging baby boomers. Crit Care Med. 2005;33:574-9.

13. Corke C, Leeuw E, Lo SK, George C. Predicting future intensive care demand in Australia. Crit Care Resusc. 2009;1:257-60.

Page $12 / 16$ 
14. Jang IY, Lee HY, Lee E. 50th Anniversary Committee of Korean Geriatrics Society. Geriatrics Fact Sheet in Korea 2018 From National Statistics. Ann Geriatr Med Res. 2019;23:50-3.

15. Park J, Jeon $\mathrm{K}$, Chung CR, Yang JH, Cho YH, Cho J, et al. A nationwide analysis of intensive care unit admissions, 2009-2014-The Korean ICU National Data (KIND) study. J Cri Care. 2018;44:24-30.

16. Halpern NA, Pastores SM, Greenstein RJ. Critical care medicine in the United States 1985-2000: an analysis of bed numbers, use, and costs. Crit Care Med. 2004;32:1254-9.

17. Kim HJ, Fay MP, Feuer EJ, Midthune DN. Permutation tests for joinpoint regression with applications to cancer rates. Stat Med. 2004;19:335-51.

18. Dwyer-Lindgren L. US county-level trends in mortality rates for major causes of death, 1980-2014. JAMA. 2016;316:2385-401.

19. Earnest A, Chen MI, Ng D, Sin LY. Using autoregressive integrated moving average (ARIMA) models to predict and monitor the number of beds occupied during a SARS outbreak in a tertiary hospital in Singapore. BMC Health Serv Res. 2005;5:36.

20. Tierney LT, Conroy KM. Optimal occupancy in the ICU: a literature review. Aust Crit Care. 2014;27:77-84.

21. Stelfox HT, Hemmelgarn BR, Bagshaw SM, Gao S, Doig CJ, Nijssen-Jordan C, et al. Intensive care unit bed availability and outcomes for hospitalized patients with sudden clinical deterioration. Arch Intern Med. 2012;172:467-74.

22. Wallace DJ, Angus DC, Seymour CW, Barnato AE, Kahn JM. Critical care bed growth in the United States. A comparison of regional and national trends. A. J Respir Crit Care Med. 2015;191:410-6.

23. Shin W. Future perspective of the older adult food in a super-aged society. J Korean Dysphagia Soc. 2021;11:1-8.

24. Linden A, Schweitzer SO. Using time series ARIMA modeling for forecasting bed-days in a Medicare HMO. AHSRHP Annual Meeting. 2001;18:25.

25. Rhodes A, Ferdinande P, Flaatten H, Guidet B, Metnitz PG, Moreno RP. The variability of critical care bed numbers in Europe. Intensive Care Med. 2012;38:1647-53.

26. Garrouste-Orgeas M, Montuclard L, Timsit JF, Reignier J, Desmettre T, Karoubi P, et al. Predictors of intensive care unit refusal in French intensive care units: A multiple-center study. Crit Care Med. 2005;33:750-5.

27. Phua J, Montuclard L, Timsit JF, Redjeki IS, Detleuxay K, Mendsaikhan N, et al. Critical care bed capacity in Asian countries and regions. Crit Care Med. 2020;48:654-62.

28. Ohbe H, Sasabuchi Y, Kumazawa R, Matsui H, Yasunaga H. Intensive care unit occupancy in Japan, 2015-2018: a nationwide inpatient database study. J Epidemiol. 2021. doi:10.2188/jea.JE20210016.

29. Yasuda S, Miyamoto Y, Ogawa H. Current status of cardiovascular medicine in the aging society of Japan. Circulation. 2018;138:965-7.

30. Sudo K, Kobayashi J, Noda S, Fukuda Y, Takahashi K. Japan's healthcare policy for the older adult through the concepts of self-help (Ji-jo), mutual aid (Go-jo), social solidarity care (Kyo-jo), and governmental care (Ko-jo). Biosci Trend. 2018;12:7-11.

31. Tanimoto T. A perspective on the benefit-risk assessment for new and emerging pharmaceuticals in Japan. Drug Des Devel Ther. 2015;9:1877-88.

32. Kim YK. Forecasting the future reimbursement system of Korean National Health Insurance: a contemplation focusing on global budget and Neo-KDRG-based payment systems. J Korean Med Sci. 2012;27(Suppl(Suppl):2532.

33. Lim CM, Kwak SH, Suh GY, Koh Y. Critical care In Korea: Present and future. J Korean Med Sci. 2015;30:1540-4. 
34. DeLia D. Annual bed statistics give a misleading picture of hospital surge capacity. Ann Emerg Med. 2006;48:384-8. 388.e1-2.

\section{Figures}

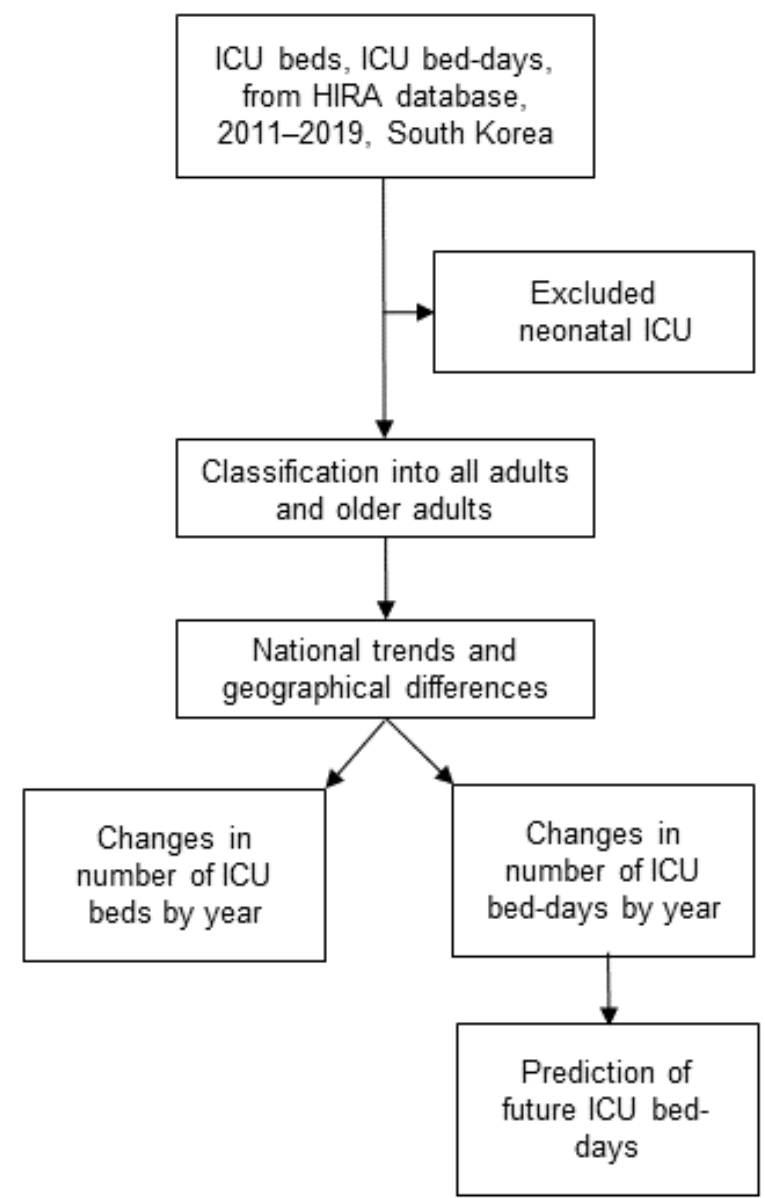

\section{Figure 1}

Flow chart of study design HIRA, Health Insurance Review and Assessment; ICU, intensive care unit 

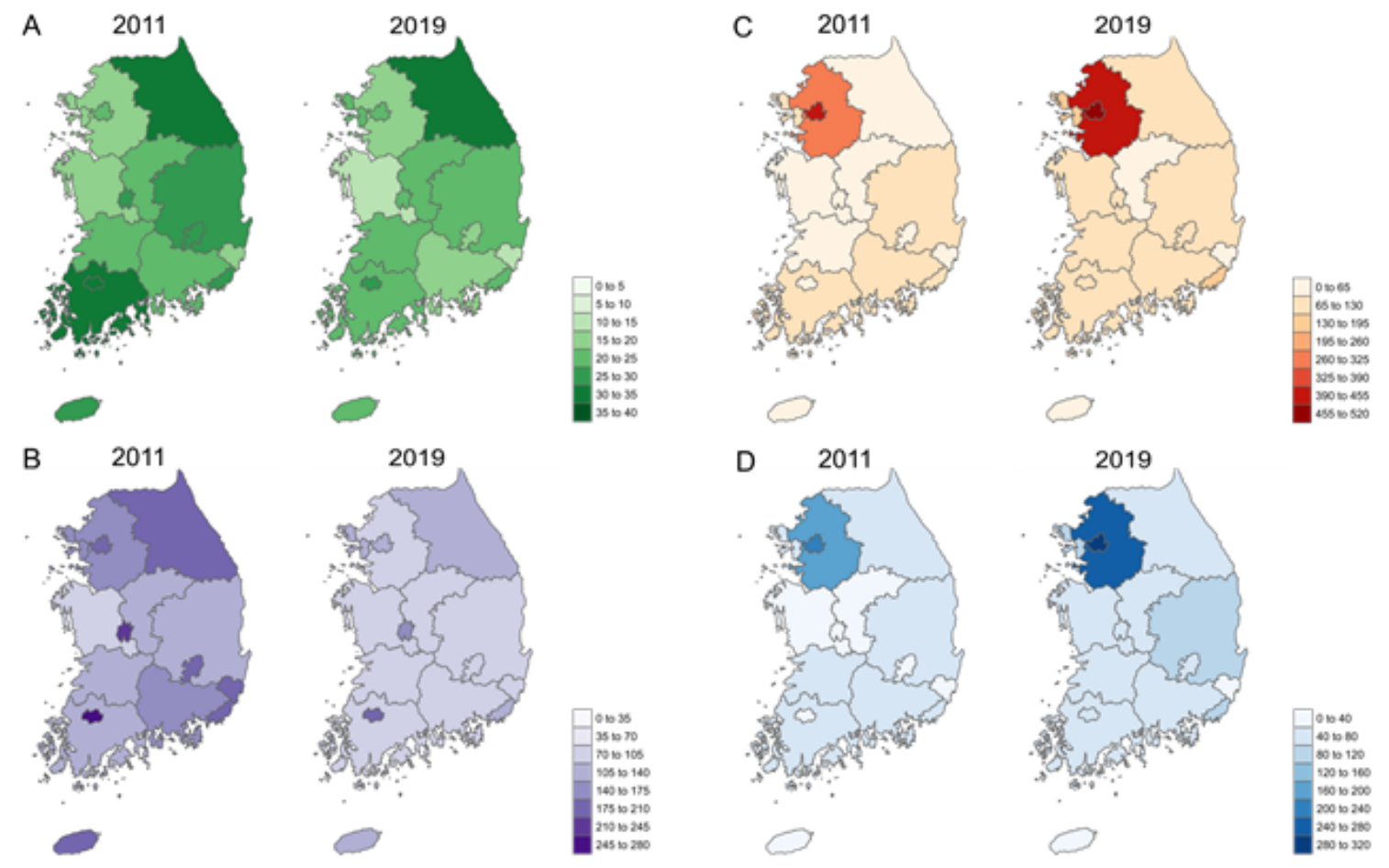

Figure 2

Changes in ICU bed rate and ICU bed-days from 2011 to 2019. (A) ICU bed rate per 100,000 of the adult population (B) ICU bed rate per 100,000 of the older adult population $(100 \mathrm{~K})$ (C) ICU bed-days of the adult population $(\times 1,000)(\mathrm{D})$ ICU bed-days of the older adult population $(\times 1,000) \mathrm{ICU}$, intensive care unit Note: The designations employed and the presentation of the material on this map do not imply the expression of any opinion whatsoever on the part of Research Square concerning the legal status of any country, territory, city or area or of its authorities, or concerning the delimitation of its frontiers or boundaries. This map has been provided by the authors.
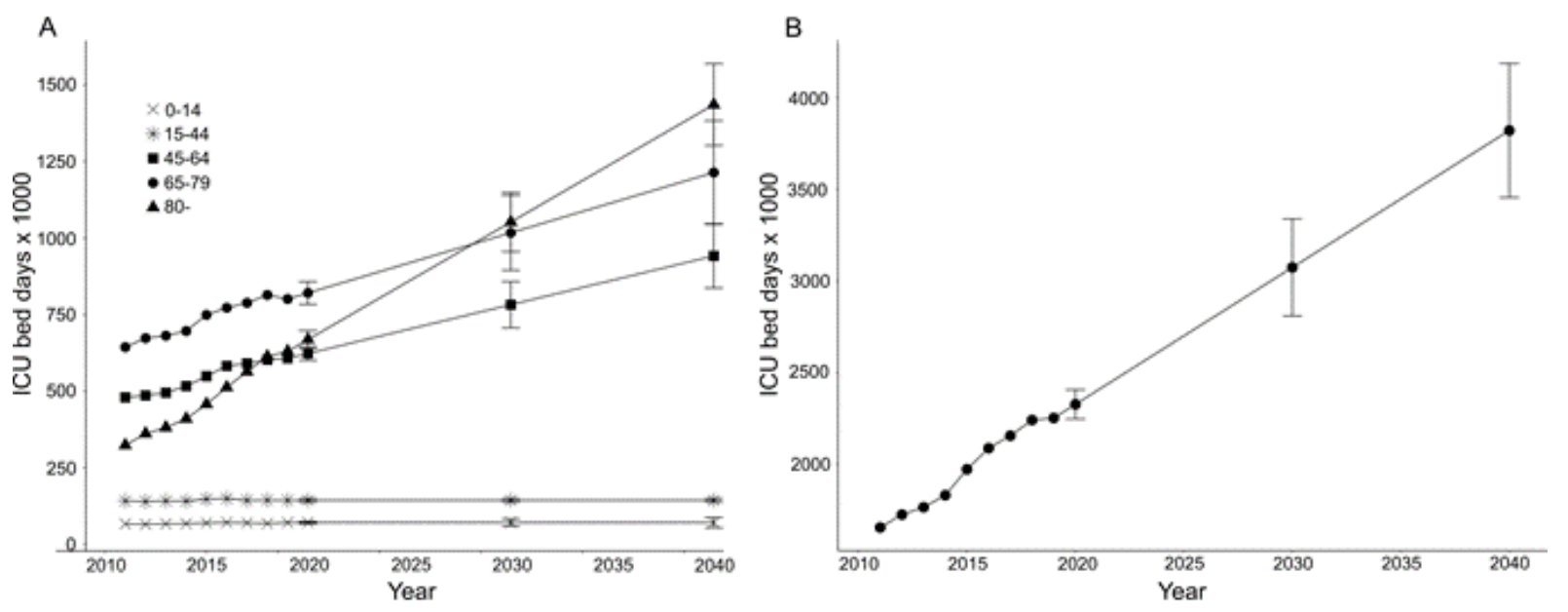

\section{Figure 3}

Number of ICU bed-days from 2011 to 2019 and projections for 2020, 2030, and 2040. (A) Each age group over time (B) Sum of ICU bed-days from each age group ICU, intensive care unit 


\section{Supplementary Files}

This is a list of supplementary files associated with this preprint. Click to download.

- Supplementarymaterial.docx 